\title{
WHICH VARIABLES PREDICT INDONESIA'S INFLATION?
}

\author{
Susan Sunila Sharma ${ }^{1}$ \\ ${ }^{1}$ Department of Finance \& Centre for Financial Econometrics, Deakin Business School, Australia. \\ Email: s.sharma@deakin.edu.au
}

\begin{abstract}
We use an exhaustive list of Indonesia's macroeconomic variables in a comparative analysis to determine which predictor variables are most important in forecasting Indonesia's inflation rate. We use monthly time-series data for 30 macroeconomic variables. Using both in-sample and out-of-sample predictability evaluations, we report consistent evidence of inflation rate predictability using 11 out of 30 macroeconomic variables.
\end{abstract}

Keywords: Macroeconomic variables; Inflation; Time-series; Predictability. JEL Classification: C5; E1.

\author{
Article history: \\ Received : December 10, 2018 \\ Revised : March 1, 2019 \\ Accepted : : March 30, 2019 \\ Available online : April 30, 2019 \\ https://doi.org/ 10.21098/bemp.v22i1.1038
}




\section{INTRODUCTION}

There is an enormous body of literature on inflation rate predictability. The literature utilizes a wide range of financial and nonfinancial variables in forecasting inflation rate (see, for instance, Goodhart and Hofmann, 2000; Barr and Campbell, 1997; Forni, Hallin, Lippi, and Reichlin, 2003; Mandalinci, 2017; Salisu and Isah, 2018; among others). The focus of this literature is on alternative models, channels, data sets, and countries to improve the forecasting performance on inflation rate. Thus, empirical evidence on the predictability of inflation rate is mixed. Overall, results are not robust with respect to model specification, sample choice, and countries considered. ${ }^{1}$

To-date, a large number of studies has examined inflation rate predictability for developed countries. These studies consider forecasting inflation rate mainly for the US (see Clark and Ravazzolo, 2015; D'Agostino, Gambetti, and Giannone, 2013) and the European region (Berg and Henzel, 2015; Caggiano, Kapetanios, and Labhard, 2011; Giannone, Lenza, Momferatou, and Onorante, 2014; Groen, Kapetanios, and Price, 2009). In the case of emerging countries, we find the focus directed mainly to South Africa (Gupta and Kabundi, 2011), Turkey (Öğünç et al., 2013) and Malaysia (Duasa, Ahmad, Ibrahim, and Zainal, 2010).

Emerging market volatility poses a problem for central banks in controlling inflation. The target inflation rate is almost never achieved. One step toward achieving inflation close to the target objective is to improve the precision of inflation forecasting. This study aims to examine the factors that successfully predict Indonesia's inflation rate. In Indonesia, the inflation target is set by the government under the Bank Indonesia Law. However, Bank Indonesia is equally responsible and committed to achieving the inflation target. For instance, in 2001, 2005 , and 2008 actual inflation was in excess of the target rate by $6.55 \%, 11.11 \%$, and $6.06 \%$, respectively. On the other hand, in 2003, 2006, 2009, 2011, 2015, and 2016, the actual inflation rate was less than the target rate, implying that, during these years, inflation targets were achieved. However, the overall statistics do not show that the inflation rate target over the last decade was met consistently. ${ }^{2}$ Several strands of literature focus on Indonesia's inflation rate. For instance, some research aims to understand the source of inflation in Indonesia (Siregar and Rajaguru, 2005a, b); other research examines the causal relation between money supply and inflation (Hossain, 2005); and third strand examines the determinants of inflation (Wimanda et al., 2011). To-date, there is limited work on forecasting Indonesia's inflation rate. Exceptions are Ramakrishnan and Vamvakidis (2002), Sari et al. (2016), and Mandalinci (2017).

Ramakrishnan and Vamvakidis (2002) examine the inflation process in Indonesia using a multivariate framework, where they regress CPI on 13 variables, including proxies for exchange rate, output gap, wages, and foreign inflation rate. Their data span the period 1980 to 2000. Their conclusion is that exchange rate and the foreign inflation rate are statistically significant predictors of inflation. Sari et al. (2016) propose the backpropagation neural network method to forecast inflation rate. They use monthly time-series inflation rate data over the period July

\footnotetext{
1 See Stock and Watson (2001) provides a survey of literature on predictability of inflation rate.

2 Source: Bank Indonesia http://www.bi.go.id/en/moneter/inflasi/data/Default.aspx.
} 
2005 to December 2013. The root mean squared error (RMSE) test statistic is used to examine the accuracy of their forecasting model. They also implement the Sugeno FIS model as a benchmark method. Their results show that the performance of their proposed method is better than the competitor model. Finally, Mandalinci (2017) examines the forecasting performance of inflation rate for nine emerging countries (Chile, India, Indonesia, Malaysia, Mexico, Philippines, South Africa, Thailand, and Turkey). Using quarterly data (1979Q2-2015Q4) and 10 econometric models, this author concludes that predictability results vary with respect to use of different econometric models and by country.

The above-mentioned studies are insufficient to understand the forecasting performance of Indonesia's inflation, for the following reasons: (i) none of the studies uses recent datasets; (ii) none of the studies models statistical issues (i.e., persistency, endogeneity, and heteroscedasticity of the inflation rate) important to forecast precision; and (iii) they all fail to conduct robustness tests to validate their forecasting results. The large void in the literature on simple and parsimonious single equation models for inflation forecasts in Indonesia is surprising. From a monetary policy point of view, such forecasting models could be useful to guide policy discussions through a set of competing views on the likely direction of future inflation based on various mixtures of predictors, as opposed to those used in the core simultaneous macroeconomic models. In other words, use of supplementary predictor models may help policy makers navigate model and shock uncertainty.

These issues constitute a research gap on inflation forecasting in Indonesia. Our goal is to fill this gap and construct a full-fledged inflation forecasting model for Indonesia. In this regard, our approach differs from the literature in four ways.

First, our approach follows a bivariate predictive regression framework. We use monthly data for 30 macroeconomic variables. We divide these 30 macroeconomic variables into five groups: (i) three measures of bond yield (separated by maturity, namely, government bond yield at one year (BY1Y), five years (BY5Y), and 10 years (BY10Y)); (ii) four measures of interest rate (separated by maturity: one month (JIBOR1), three months (JIBOR3), six months (JIBOR6), and 12 months (JIBOR12)); (iii) two proxies for monetary aggregates (monetary aggregate (M1 and LM2)); (iv) 12 monetary/trade-related variables (consumer confidence index (LCCI), Indonesia's three-month time deposits (TD3M), industrial production (LIP), exchange rate (LER), export of goods (LEXP), export price index (EXPPI), import of goods (LIMP), import price index (IMPPI), lending rate (LR), producer price index (PP, excludes oil), foreign exchange reserves (FER, excludes gold), and Indonesia's currency in circulation (LCIC)); and (v) nine financial variables (business confidence index (LBCI), Jakarta stock exchange capitalization (LCAP), cash return index (LCRI), dividend yield (DY), Dow Jones Indonesia stock index (LDJSI), market capitalization to GDP (MCAP), Jakarta Stock Exchange Islamic index (LISI), composite index (LCI); and price-to-earnings ratio (PER)).

Second, we use a newly developed estimator proposed by Westerlund and Narayan (WN, 2012 and 2015) - a flexible generalized least squares (WN-FGLS) estimator - to examine the null hypothesis of no predictability. The key advantage of the WN-FGLS is that it allows us to control for three statistical aspects of the data and model that matter directly in the forecasting exercise. These issues relate to endogeneity already recognized as an issue in the predictability literature, 
persistency of predictor variables such that, instead of diluting the information contained in predictor variables, we can use the variables in their level form, and heteroscedasticity - an issue recognized as a stylized fact in financial time-series data (see Salisu and Isah, 2018; Sharma, 2016).

Third, we test for both in-sample and out-of-sample predictability. This is important because in-sample predictability does not imply that the model performs equally well in out-of-sample tests. We use two measures of out-ofsample evaluations: relative Theil U (RTU) and out-of-sample R-squared (OOSR2) statistics. Finally, we conduct robustness checks of in-sample and out-of-sample predictability test results. Here, we examine in-sample predictability using different forecasting horizons (three-month-ahead and six-month-ahead) and we increase the estimation window from $50 \%$ to $70 \%$ of the data sample to generate out-of-sample test statistics.

Our study contributes to the strand of literature that examines the predictability of Indonesia's inflation rate. Our approaches produce three main findings. First, we uncover strong evidence of in-sample predictability (when $h=1$ ) of inflation rate using 22/30 macroeconomic variables. More specifically, we conclude that none of the group 1 (bond yield) variables are statistically significant, whereas from the other four groups, the majority of variables significantly predict inflation rate. Second, we consider results for out-of-sample evaluations. Here, we use $50 \%$ of the sample to generate recursive forecasts of the remaining $50 \%$ of the sample. Our findings are inconsistent with respect to the use of two measures of out-of-sample evaluations. More specifically, according to the RTU and OOSR2 statistics, our proposed macroeconomic predictor-based model outperforms the benchmark constant-only model in 7/30 and 11/30 cases. Therefore, we consider this weak evidence when compared with in-sample predictability results. Hence, it becomes very important to check the robustness of our findings. Finally, we consider in-sample predictability for two additional forecasting horizons, $h=3$ and $h=6$. Our findings remain unchanged and are robust to the in-sample predictability results when $h=1$. Next, to check the robustness of our out-of-sample evaluations, we increase the estimation window from $50 \%$ to $70 \%$ of the sample and generate recursive forecasts for the remaining 30\% of the sample. Given that we have now increased the number of observations in the estimation window, our out-of-sample evaluations improve notably. Note that our proposed macroeconomic predictorbased model outperforms a constant-only model in 21/30 cases. In summary, we find that for 11 macroeconomic variables (LBCI, LCAP, LCRI, LDJSI, LISI, JIBOR1, JIBOR3, JIBOR6, JIBOR12, LM2, and FER) we note evidence of both in-sample and out-of-sample predictability.

This paper proceeds as follows. Section II discusses data and methodology. We discuss our main findings in Section. Finally, Section IV sets forth our conclusions.

\section{DATA AND METHODOLOGY}

A. Data Set

We demonstrate the importance of our new predictability model for Indonesia's inflation rate using 30 macroeconomic variables. These predictor variables are divided into the following five categories: 
(i) Three measures of bond yield, separated by maturity: BY1Y, BY5Y, and BY10Y

(ii) Four measures of interest rate, separated by maturity: JIBOR1, JIBOR3, JIBOR6, and JIBOR12

(iii) Two proxies for monetary aggregates: M1 and LM2

(iv) Twelve monetary/trade-related variables: LCCI, TD3M, LIP, LER, LEXP, EXPPI, LIMP, IMPPI, LR, PP (excludes oil), FER (excludes gold), and LCIC

(v) Nine financial variables: LBCI, LCAP, LCRI, DY, LDJSI, MCAP, LISI, LCI, and PER

Our data are taken from Sharma, Tobing, and Azwar (2018). These authors note that the data are extracted from the Global Financial Database and the choice of dataset is based purely on data availability. We provide detailed information on our dataset in Table 1.

Table 1.

Data Description

This table provides detail data description of all variables considered in this study.

\begin{tabular}{|c|c|c|c|}
\hline Variables & Description & Date & No. of obs. \\
\hline BY1Y & One-year government bond yield & 2009M05-2018M06 & 110 \\
\hline BY5Y & Five-year government bond yield & 2009M05-2018M06 & 110 \\
\hline BY10Y & Ten-year government bond yield & 2009M05-2018M06 & 110 \\
\hline JIBOR1 & One-month JIBOR & 1990M01-2018M06 & 342 \\
\hline JIBOR3 & Three-month JIBOR & 1993M12-2018M06 & 295 \\
\hline JIBOR6 & Six-month JIBOR & 1991M01-2018M06 & 330 \\
\hline JIBOR12 & Twelve-month JIBOR & 1997M03-2018M06 & 256 \\
\hline LM2 & M2 money supply in natural logarithm & 2003M12-2018M04 & 173 \\
\hline M1 & M1 money supply & 2008M01-2018M04 & 124 \\
\hline LCCI & Indonesia consumer confidence index in natural logarithm & 2001M04-2017M12 & 201 \\
\hline LCIC & Indonesia currency in circulation in natural logarithm & 2002M01-2018M05 & 197 \\
\hline TD3M & Three-month time deposits & 1974M04-2016M07 & 508 \\
\hline LEXP & Export of goods in natural logarithm & 1967M02-2018M05 & 616 \\
\hline LER & Indonesian rupiah per USD in natural logarithm & 1967M02-2018M06 & 617 \\
\hline IMPPI & Import price index & 1991M01-2018M05 & 329 \\
\hline EXPPI & Export price index & 1991M01-2018M05 & 329 \\
\hline LIMP & Imports of good in natural logarithm & 1967M02-2018M05 & 616 \\
\hline LIP & Industrial production in natural logarithm & 1991M12-2018M04 & 317 \\
\hline LR & Average lending rate for working capital & 1986M03-2016M08 & 366 \\
\hline PP & Producer prices (excludes oil) & 1971M01-2016M04 & 544 \\
\hline FER & Total foreign exchange reserves (excludes gold) & 1971M01-2018M06 & 570 \\
\hline $\mathrm{LBCI}$ & Business confidence index in natural logarithm & 2002M03-2017M12 & 190 \\
\hline LCAP & $\begin{array}{c}\text { Jakarta stock exchange capitalization (value traded, USD) in } \\
\text { natural logarithm }\end{array}$ & 1990M01-2018M05 & 341 \\
\hline LCRI & Indonesia cash return index in natural logarithm & 1989M12-2018M06 & 343 \\
\hline LCI & Jakarta stock exchange composite index in natural logarithm & 1983M03-2018M06 & 424 \\
\hline LDJSI & Dow Jones Indonesia stock index in natural logarithm & 1992M01-2018M06 & 318 \\
\hline DY & Dividend yield & 1990M11-2018M06 & 332 \\
\hline LISI & Jakarta stock exchange Islamic index in natural logarithm & 2000M07-2018M06 & 216 \\
\hline MCAP & Market capitalization measured as percentage of GDP & 1995M01-2018M05 & 281 \\
\hline PER & Price-to-earnings ratio & 1990M01-2018M06 & 342 \\
\hline INF & Change in consumer price index & 1967M02-2018M06 & 617 \\
\hline
\end{tabular}




\section{B. Methodology}

The starting point for developing our inflation rate forecasting model for Indonesia is to create an extensive dataset of predictors of inflation. To accomplish this, we identify 30 predictor variables. Such an exhaustive list provides a comparative analysis to understand which predictor variables are most important. This is important because it will reveal which variables policy makers should track to forecast inflation. Our predictive regression model will take the following form:

$$
I n_{t}=\alpha+\beta X_{t-1}+\varepsilon_{t}
$$

Here $I n_{t}$ is Indonesia's inflation rate at time $t, X_{t-1}$ is the one-period lag predictor variable, and $\varepsilon_{t}$ is the disturbance term. In our analysis, because we use 30 predictor variables, the model will be estimated 30 times.

We use a newly developed estimator proposed by WN (2012, 2015), the WNFGLS estimator, to examine the null hypothesis of no predictability. ${ }^{3}$ The key advantage of the WN-FGLS is that it allows us to control for three statistical aspects of the data and model that are important to the forecasting exercise. These issues relate to endogeneity already recognized as an issue in the predictability literature (see Sharma, 2016); persistency of predictor variables such that instead of diluting the information contained in predictor variables, we can use the variables in their level form; and heteroscedasticity - an issue recognized as a stylized fact in financial time-series data (see, e.g., Devpura et al., 2018; Phan, Sharma, Tran, 2018; Sharma, 2016; among others).

\section{MAIN FINDINGS}

This section comprises three subsections. We discuss several key statistical features of predictor variables in first subsection, followed by the main predictability results in second subsection. The final subsection discusses our robustness check.

\section{A. Statistical Features of the Data}

To examine the null hypothesis of no predictability, it is essential to first ascertain several commonly known key features of time-series data: persistency, endogeneity, and heteroskedasticity. This is essential, as these key issues distort the main results if not correctly accounted for in the predictability model of inflation rate. We first check whether our 30 predictor variables are persistent. To do so, we examine the null hypothesis of "unit root" using an Augmented-Dickey-Fuller (ADF, 1981) unit root test; we also estimate a first-order autoregressive (AR (1)) model for all variables. These results are reported in Table 3. Note that the AR (1) coefficient for all variables is close to 1 , which indicates that all 30 predictor variables are highly persistent. Next, we interpret ADF unit root test results from column 3 . We report ADF test statistics, their corresponding $p$-values, and estimated lag length. Lag

\footnotetext{
3 We do not discuss the derivation of the NW-FGLS estimator in detail because this has been explicitly explained and discussed in number of journal articles (see for instance, Devpura et al., 2018; Sharma, 2016; Phan, Sharma, Tran, 2018). In addition, the model has been extensively explained in the original paper of Westerlund and Narayan (2012, 2015).
} 
length is attained using the Schwarz information criterion, where we begin with a maximum of 14 lags. We find that the null hypothesis of "unit root" is statistically significantly rejected at the 5\% significance level (or better) in 6/30 predictors (JIBOR12, LCCI, LIP, FER, DY and PER), which implies that these six predictor variables follow a stationary process. In other words, our results imply that $80 \%$ $(24 / 30)$ of the considered predictor variables follow a non-stationary process.

\section{Table 2.}

Unit Root Test Results

This table reports the first-order autoregressive (AR(1)) coefficient of all variables and as well as results for the ADF unit root test in columns 2 and 3, respectively. The ADF unit root test examines the null hypothesis of "unit root." We examine the ADF test using a maximum of 14 lags and then use the Schwartz Information Criterion to determine the optimal lag length.

\begin{tabular}{|c|c|c|c|c|c|}
\hline Group & Variables & AR (1) & $t$-statistic & $\begin{array}{l}\text { ADF unit root test } \\
\text { lag length }\end{array}$ & $p$-value \\
\hline 1 & BY1Y & 0.8207 & -3.019 & 0 & 0.1318 \\
\hline 1 & BY5Y & 0.9161 & -2.2925 & 0 & 0.4341 \\
\hline 1 & BY10Y & 0.9172 & -2.2831 & 0 & 0.4392 \\
\hline 2 & JIBOR1 & 0.9539 & -3.2797 & 0 & 0.0714 \\
\hline 2 & JIBOR3 & 0.9638 & -2.992 & 0 & 0.1361 \\
\hline 2 & JIBOR6 & 0.9754 & -2.3724 & 0 & 0.3934 \\
\hline 2 & JIBOR12 & 0.9789 & -3.5075 & 11 & 0.0408 \\
\hline 3 & LM2 & 1.0009 & 0.6157 & 12 & 0.9995 \\
\hline 3 & M1 & 0.9952 & 1.6489 & 12 & 0.7670 \\
\hline 4 & LCCI & 0.9104 & -4.1508 & 1 & 0.0063 \\
\hline 4 & LCIC & 0.9932 & -1.3751 & 14 & 0.8651 \\
\hline 4 & TD3M & 0.9886 & -2.9195 & 1 & 0.1571 \\
\hline 4 & LEXP & 0.9968 & -2.5676 & 14 & 0.2955 \\
\hline 4 & LER & 0.9971 & -2.5483 & 9 & 0.3046 \\
\hline 4 & IMPPI & 0.9891 & -1.825 & 0 & 0.6905 \\
\hline 4 & EXPPI & 0.9949 & -2.4495 & 2 & 0.3533 \\
\hline 4 & LIMP & 0.9973 & -2.7882 & 17 & 0.2022 \\
\hline 4 & LIP & 1.0028 & -3.5392 & 3 & 0.0370 \\
\hline 4 & LR & 0.9949 & -3.0923 & 2 & 0.1097 \\
\hline 4 & $\mathrm{PP}$ & 1.0063 & 1.2217 & 1 & 1.0000 \\
\hline 4 & FER & 0.9942 & -4.6199 & 7 & 0.0010 \\
\hline 5 & LBCI & 0.9526 & -3.3006 & 9 & 0.0694 \\
\hline 5 & LCAP & 0.9895 & -3.0235 & 1 & 0.1273 \\
\hline 5 & LCRI & 0.9968 & -1.3173 & 1 & 0.8819 \\
\hline 5 & LCI & 0.9985 & -2.5475 & 1 & 0.3050 \\
\hline 5 & LDJSI & 0.9941 & -2.3923 & 0 & 0.3828 \\
\hline 5 & DY & 0.9259 & -4.1745 & 0 & 0.0054 \\
\hline 5 & LISI & 0.9928 & -1.5065 & 1 & 0.8247 \\
\hline 5 & MCAP & 0.9777 & -1.5738 & 0 & 0.801 \\
\hline \multirow[t]{2}{*}{5} & PER & 0.8878 & -5.8958 & 2 & 0.0000 \\
\hline & INF & 0.1538 & -7.9886 & 14 & 0.0000 \\
\hline
\end{tabular}


Next, we examine whether our predictor variables are endogenous, in two steps. First, we extract residuals by estimating two models: (i) our predictability model, as represented by Equation 1, and (ii) an AR(1) model of the predictor variable, which takes the following form: $X_{t}=\pi(1-\rho)+\rho X_{t-1}+\mu_{t}$. In the second step, we regress $\varepsilon_{t}$ on $\mu_{t}$. The estimated coefficient of $\mu_{t}$ and its corresponding $p$-value determine whether our predictors are endogenous. We report these results in column 2 of Table 3. Our findings suggest that we comfortably reject the null hypothesis that slope coefficient is zero for 12/30 predictor variables (BY5Y, BY10Y, LCI, LCIC, TD3M, LDJSI, IMPPI, JIBOR1, JIBOR3, JIBOR6, JIBOR12, and LR).

Table 3.

\section{Endogeneity and Heteroskedasticity Test Results}

This table reports test results for endogeneity and heteroskedasticity in columns 3 and 4, respectively. The endogeneity test is conducted by regressing the error term from the predictor regression model on the error term from the AR(1) model of the predictor variable. The heteroskedasticity test is performed based on the Lagrange multiplier test, which examines the null hypothesis of "no $\mathrm{ARCH}^{\prime \prime}$ at the lag of 6 . We do this by estimating an AR(1) model of all predictor variables. Finally, ${ }^{*}, * *$, and ${ }^{* * *}$ denote statistical significance at the $10 \%, 5 \%$, and $1 \%$ levels, respectively.

\begin{tabular}{lccccc}
\hline \multirow{2}{*}{ Group } & Variables & \multicolumn{2}{c}{ Endogeneity Test } & \multicolumn{2}{c}{ Heteroskedasticity Test } \\
\cline { 3 - 6 } & & Coefficient & $p$-value & ARCH (6) & $p$-value \\
\hline 1 & BY1Y & 0.133 & 0.1692 & 6.6628 & 0.3532 \\
1 & BY5Y & $0.2461^{* *}$ & 0.0230 & 6.5449 & 0.3650 \\
1 & BY10Y & $0.2069^{*}$ & 0.0618 & 4.1442 & 0.6572 \\
2 & JIBOR1 & $0.6786^{* * *}$ & 0.0000 & $64.033^{* * *}$ & 0.0000 \\
2 & JIBOR3 & $0.7755^{* * *}$ & 0.0000 & $61.404^{* * *}$ & 0.0000 \\
2 & JIBOR6 & $0.6729^{* * *}$ & 0.0000 & $62.412^{* * *}$ & 0.0000 \\
2 & JIBOR12 & $0.6350^{* * *}$ & 0.0000 & $57.3967^{* * *}$ & 0.0000 \\
3 & LM2 & -4.0095 & 0.1985 & $22.041^{* * *}$ & 0.0012 \\
3 & M1 & 0.5398 & 0.7541 & 8.9027 & 0.1791 \\
4 & LCCI & -18.745 & 0.1344 & 0.0299 & 1.0000 \\
4 & LCIC & $3.0560^{* * *}$ & 0.0002 & $38.976^{* * *}$ & 0.0000 \\
4 & TD3M & $0.6821^{* * *}$ & 0.0004 & $35.610^{* * *}$ & 0.0000 \\
4 & LEXP & 4.4346 & 0.2453 & $245,36^{* * *}$ & 0.0000 \\
4 & LER & -0.1984 & 0.9260 & $85.652^{* * *}$ & 0.0000 \\
4 & IMPPI & $-6.4749^{* * *}$ & 0.0009 & 0.0399 & 1.0000 \\
4 & EXPPI & -3.954 & 0.1631 & $11.183^{*}$ & 0.0829 \\
4 & LIMP & 0.1624 & 0.9503 & $120.80^{* * *}$ & 0.0000 \\
4 & LIP & -17.3765 & 0.2650 & $189.34^{* * *}$ & 0.0000 \\
4 & LR & $1.3571^{* * *}$ & 0.0000 & 2.9878 & 0.8104 \\
4 & PP & $0.2058^{* * *}$ & 0.0000 & $38.135^{* * *}$ & 0.0000 \\
4 & FER & 0.5883 & 0.7422 & $206.8^{* * *}$ & 0.0000 \\
5 & LBCI & -15.079 & 0.4199 & $42.126^{* * *}$ & 0.0000 \\
5 & LCAP & -1.0106 & 0.1661 & $58.717^{* * *}$ & 0.0000 \\
5 & LCRI & 44.492 & 0.1821 & $287.77^{* * *}$ & 0.0000 \\
5 & LCI & $-1.5887^{* *}$ & 0.0904 & 1.6178 & 0.9513 \\
5 & LDJSI & $-1.5424^{*}$ & 0.0550 & $35.873^{* * *}$ & 0.0000 \\
5 & DY & 0.3377 & 0.1272 & $57.041^{* * *}$ & 0.0000 \\
5 & LISI & -1.3788 & 0.1184 & $13.978^{* *}$ & 0.0299 \\
5 & MCAP & -6.8376 & 0.5240 & 0.0177 & 1.0000 \\
& PER & -0.0253 & 0.4762 & 6.9016 & 0.3300 \\
\hline & & & &
\end{tabular}


Finally, we conduct a heteroskedasticity test. We compute heteroskedasticity by running an AR(1) model of predictor variables and we subject the residuals to an autoregressive conditional heteroskedasticity $(\mathrm{ARCH})$ test at lag of six. The $\mathrm{ARCH}$ test is a Lagrange multiplier-based test that examines the null hypothesis of no ARCH. These results are reported in the final column of Table 3 . We reject the null hypothesis of no ARCH in $67 \%$ of the cases (20/30 predictors), which implies that these 20 predictors are heteroskedastic. The exceptions are: BYIY, BY5Y, BY10Y, LCCI, LCI, IMPPI, LR, MCAP, PER, and M1.

First, we conclude from our preliminary results that all our predictor variables are highly persistent. Second, our findings suggest that the issue of endogeneity and heteroskedasticity is dependent on the macroeconomic variable used in the predictability model of inflation rate. Thus, overall, our results imply that we cannot ignore these salient features of the data in estimating the predictability model of inflation rate using the 30 available macroeconomic variables for Indonesia. Therefore, this becomes the main motivation for our use of the WN $(2012,2015)$ predictability model, as it simultaneously accounts for all these three statistical features of time-series data.

\section{B. Predictability Test Results}

Here we discuss results for in-sample and out-of-sample predictability test results. First, we discuss the in-sample predictability test results, determined using the WN $(2012,2015)$ model. We specifically report the WN-FGLS coefficient (at onemonth-ahead forecasts $(h=1)$ ) and its corresponding $p$-values in Table 4 . Earlier in Section II, we mentioned that we categorize our data into five groups. Therefore, our aim here is to examine which group of macroeconomic variables is found to statistically significantly predict Indonesia's inflation rate.

Our findings are as follows. First, we note that none of the group 1 (bond yield) predictor variables are found to be statistically significant. Second, all proxies for interbank interest rate (group 2) are found to be statistically significant at the $1 \%$ level, which implies JIBOR (irrespective of maturity) is a statistically significant predictor of inflation rate. Third, LM2 significantly predicts inflation rate at the $5 \%$ significance level, whereas M1 is reported to be a statistically insignificant predictor from group 3 (monetary aggregate). Fourth, we find that fully 11 (except LCCI) monetary and trade-related macroeconomic variables (group 4) are statistically significant predictors of inflation rate. More specifically, we find that $9 / 11$ group 4 predictors (TD3M, LEXP, LER, IMPPI, EXPPI, LIMP, LR, PP, FER) are statistically significant at the $1 \%$ significance level, whereas, $2 / 11$ variables (LCIC and LIP) are statistically significant at the $10 \%$ significance level. Finally, out of nine financial variables (group 5), we find six variables significantly predict Indonesia's inflation rate. In particular, we find LCAP, LDJSI, and LISI are statistically significant at the $1 \%$ level, whereas, LBCI and LCRI, and LCI are statistically significant at the $10 \%$ and $5 \%$ levels, respectively. 
Table 4.

In-sample Predictability Test Results

This table reports in-sample predictability test results obtained using the WN $(2012,2015)$ predictability model when $h=1$. More specifically, we report the WN-FGLS estimator with its corresponding $p$-value, which determines the null hypothesis of "no predictability." Finally, ${ }^{*}, * *$, and ${ }^{* * *}$ denote statistical significance at the $10 \%, 5 \%$, and $1 \%$ levels, respectively.

\begin{tabular}{lccccccc}
\hline Group & Variables & Coefficient & $p$-value & Group & Variables & Coefficient & $p$-value \\
\hline 1 & BY1Y & 0.0192 & 0.8485 & 4 & EXPPI & $-0.2369^{* * *}$ & 0.0000 \\
1 & BY5Y & 0.0503 & 0.6063 & 4 & LIMP & $-0.2173^{* * *}$ & 0.0000 \\
1 & BY10Y & 0.0501 & 0.6105 & 4 & LIP & $-0.0916^{*}$ & 0.0795 \\
2 & JIBOR1 & $0.5129^{* * *}$ & 0.0000 & 4 & LR & $0.2787^{* * *}$ & 0.0000 \\
2 & JIBOR3 & $0.4787^{* * *}$ & 0.0000 & 4 & PP & $-0.2229^{* * *}$ & 0.0000 \\
2 & JIBOR6 & $0.4523^{* * *}$ & 0.0000 & 4 & FER & $-0.1644^{* * *}$ & 0.0001 \\
2 & JIBOR12 & $0.4546^{* * *}$ & 0.0000 & 5 & LBCI & $-0.1292^{*}$ & 0.0807 \\
3 & LM2 & $-0.2174^{* *}$ & 0.0394 & 5 & LCAP & $-0.2421^{* * *}$ & 0.0000 \\
3 & M1 & -0.1118 & 0.2143 & 5 & LCRI & $0.0845^{*}$ & 0.0980 \\
4 & LCCI & -0.0777 & 0.2861 & 5 & LCI & $-0.1028^{* *}$ & 0.0346 \\
4 & LCIC & $-0.1262^{*}$ & 0.0685 & 5 & LDJSI & $-0.2063^{* * *}$ & 0.0002 \\
4 & TD3M & $0.1885^{* * *}$ & 0.0000 & 5 & DY & 0.044 & 0.4347 \\
4 & LEXP & $-0.2084^{* * *}$ & 0.0000 & 5 & LISI & $-0.1821^{*}$ & 0.0077 \\
4 & LER & $-0.1541^{* * *}$ & 0.0001 & 5 & MCAP & -0.0789 & 0.2070 \\
4 & IMPPI & $-0.2897^{* * *}$ & 0.0000 & 5 & PER & -0.0481 & 0.4006 \\
\hline
\end{tabular}

Overall, we conclude from the above discussion that 22/30 macroeconomic variables are statistically significant predictors of Indonesia's inflation rate. When we consider results as per the five groups, we conclude that none of the group 1 (bond yield) variables are statistically significant, whereas from the other four groups, the majority of the variables significantly predict inflation rate.

Next, we turn to out-of-sample evaluations. We consider two out-of-sample evaluations: RTU and OOSR2. Our approach in computing RTU and OOSR2 is as follows. We use $50 \%$ of in-sample data to generate recursive forecasts of inflation rate for the remaining $50 \%$ of the sample. We compare the forecasting performance of our proposed macroeconomic predictor-based model with an inflation rate constant-only model. We define RTU as a ratio of Theil U statistics from our proposed predictability model $\left(T U_{M}\right)$ relative to Theil $\mathrm{U}$ statistics from the inflation rate constant-only model $\left(T U_{C}\right)$. This can be represented as $R T U=T U_{M} /$ $T U_{C}$. We compute OOSR2 statistics as OOSR2 $=\left(1-\left(R M S E_{M} / R M S E_{C}\right)\right.$, where $R M S E_{M}$ and $R M S E_{C}$ denote RMSEs from our proposed macroeconomic predictor-based model vis-à-vis inflation rate constant-only model, respectively. Hence, from the above definitions of RTU and OOSR2, it is implied that when RTU is less than 1 and OOSR2 is greater than zero, the forecasts from our proposed macroeconomic predictor-based model are superior to those obtained from the inflation rate constant-only model. We report RTU and OOSR2 statistics in Table 5. 
Table 5.

\section{Out-of-Sample Evaluations}

This table reports results for two measures of out-of-sample predictability, namely relative Theil U (RTU) and out-of-sample R-squared (OOSR2) statistics. The RTU and OOSR2 statistics measure the performance of our predictive regression model vis-àvis the constant-only model. The out-of-sample period considered is $50 \%$ of the sample. The results are reported for a one-period forecasting horizon, $h=1$.

\begin{tabular}{lccccccc}
\hline Group & Variables & RTU & OOSR2 & Group & Variables & RTU & OOSR2 \\
\hline 1 & BY1Y & 0.9760 & -0.0036 & 4 & EXPPI & 1.8857 & -3.4133 \\
1 & BY5Y & 0.9777 & -0.0083 & 4 & LIMP & 1.5891 & -0.1416 \\
1 & BY10Y & 0.9817 & -0.0019 & 4 & LIP & 1.1211 & -0.5181 \\
2 & IIBOR1 & 1.4368 & 0.0906 & 4 & LR & 1.6994 & -0.1262 \\
2 & JIBOR3 & 1.1155 & 0.3331 & 4 & PP & 1.5407 & -3.3524 \\
2 & JIBOR6 & 1.3138 & 0.1146 & 4 & FER & 1.2298 & 0.0081 \\
2 & JIBOR12 & 1.0090 & 0.3666 & 5 & LBCI & 1.0011 & 0.0286 \\
3 & LM2 & 1.0620 & 0.1093 & 5 & LCAP & 1.3150 & 0.0894 \\
3 & M1 & 1.2589 & -0.0310 & 5 & LCRI & 1.6383 & 0.0121 \\
4 & LCCI & 1.1700 & -0.2408 & 5 & LCI & 1.0526 & -0.2757 \\
4 & LCIC & 0.9682 & -0.0457 & 5 & LDJSI & 1.5348 & 0.0266 \\
4 & TD3M & 1.0691 & -0.0902 & 5 & DY & 0.9963 & -0.0851 \\
4 & LEXP & 1.6553 & -0.0896 & 5 & LISI & 0.9925 & 0.0366 \\
4 & LER & 1.6011 & -0.7833 & 5 & MCAP & 2.0929 & -17.2207 \\
4 & IMPPI & 1.4012 & -0.0914 & 5 & PER & 0.9984 & -0.0050 \\
\hline
\end{tabular}

Contrary to our in-sample predictability test results, the evidence in favor of our proposed macroeconomic predictor-based forecasts is weak. More specifically, we find RTU statistics of less than 1 in only $7 / 30$ predictability models. This implies that our proposed macroeconomic predictor-based model outperforms the constant-only model only when we consider BY1Y, BY5Y, BY10Y, LCIC, DY, LISI, and PER as predictors of Indonesia's inflation rate. Additionally, with respect to the OOSR2 statistics, our findings suggest that forecasting performance of our proposed predictability model is superior to the performance of a constant-only model in 11/30 cases. In other words, the predictability model that considers LBCI, LCAP, LCRI, LDJSI, LISI, JIBOR1, JIBOR3, JIBOR6, JIBOR12, LM2, and FER as predictors of inflation rate outperforms the constant-only model. The two measures of out-of-sample evaluation provide mixed evidence in support of our proposed macroeconomic predictor-based model.

From our overall empirical results, we find that in-sample and at least one out of two measures of out-of-sample evaluations provide strong evidence in support of 12/30 macroeconomic variables (LBCI, LCAP, LCRI, LCIC, LDJSI, LISI, JIBOR1, JIBOR3, JIBOR6, JIBOR12, LM2, and FER) as statistically significant predictors of Indonesia's inflation rate.

\section{Robustness Check}

For the sake of completeness, we perform a robustness check of our findings as discussed above. We conduct a robustness test for both in-sample and out-ofsample predictability evaluations. First, we discuss our in-sample robustness test. Above, we consider predictability at $h=1$. Thus, in this subsection, we would like 
to ascertain whether our results remain unchanged when $h=3$ and $h=6$. We report these results in Table 6 . Interestingly, our findings remain unchanged. When $h=3$ and $h=6$, we find that $21 / 30$ macroeconomic variables are statistically significant predictors of Indonesia's inflation rate. The only exception is the predictor variable LBCI, which is statistically insignificant when $h=3$ and $h=6$ and is found to be a statistically significant predictor of inflation rate when $h=1$. Therefore, we conclude that in-sample predictability results are robust to different forecasting horizons.

Table 6.

\section{Robustness Check for In-Sample Predictability Test Results}

This table reports the WN $(2012,2015)$ in-sample predictability test results when $h=3$ and $h=6$. And, ${ }^{*}, * *$, and ${ }^{* * *}$ denote statistical significance at the $10 \%, 5 \%$, and $1 \%$ levels, respectively.

\begin{tabular}{|c|c|c|c|c|c|}
\hline \multirow{2}{*}{ Group } & \multirow{2}{*}{ Variables } & \multicolumn{2}{|c|}{$h=3$} & \multicolumn{2}{|c|}{$h=6$} \\
\hline & & Coefficient & $p$-value & Coefficient & $p$-value \\
\hline 1 & BY1Y & -0.0432 & 0.6632 & -0.0268 & 0.7888 \\
\hline 1 & BY5Y & -0.0186 & 0.8499 & 0.0027 & 0.9787 \\
\hline 1 & BY10Y & -0.0184 & 0.8527 & 0.0142 & 0.8889 \\
\hline 2 & JIBOR1 & $0.3641^{* * *}$ & 0.0000 & $0.9409^{* * *}$ & 0.0000 \\
\hline 2 & JIBOR3 & $0.3409^{* * *}$ & 0.0000 & $0.0553^{* * *}$ & 0.0000 \\
\hline 2 & JIBOR6 & $0.3444^{* * *}$ & 0.0000 & $0.2979^{* * *}$ & 0.0000 \\
\hline 2 & JIBOR12 & $0.3513^{* * *}$ & 0.0000 & $0.3291^{* * *}$ & 0.0000 \\
\hline 3 & LM2 & $-0.2207^{* *}$ & 0.0342 & $-0.1837^{*}$ & 0.0748 \\
\hline 3 & M1 & -0.1372 & 0.1362 & -0.0373 & 0.6775 \\
\hline 4 & LCCI & 0.0574 & 0.4430 & -0.0099 & 0.8881 \\
\hline 4 & LCIC & $-0.1598^{* *}$ & 0.0219 & $-0.1747^{* *}$ & 0.0142 \\
\hline 4 & TD3M & $0.1559^{* * *}$ & 0.0004 & $0.0873^{*}$ & 0.0523 \\
\hline 4 & LEXP & $-0.2089^{* * *}$ & 0.0000 & -0.2102 & 0.0000 \\
\hline 4 & LER & $-0.1702^{* * *}$ & 0.0000 & $-0.1801^{* * *}$ & 0.0000 \\
\hline 4 & IMPPI & $-0.2022^{* * *}$ & 0.0002 & $-0.1509^{* * *}$ & 0.0065 \\
\hline 4 & EXPPI & $-0.2105^{* * *}$ & 0.0001 & $-0.1916^{* * *}$ & 0.0006 \\
\hline 4 & LIMP & $-0.2175^{* * *}$ & 0.0000 & $-0.2206^{* * *}$ & 0.0000 \\
\hline 4 & LIP & $-0.0968^{*}$ & 0.0671 & $-0.1169^{* *}$ & 0.0302 \\
\hline 4 & LR & $0.2561^{* * *}$ & 0.0000 & $0.1923^{* * *}$ & 0.0002 \\
\hline 4 & PP & $-0.2327^{* * *}$ & 0.0000 & $-0.2509^{* * *}$ & 0.0000 \\
\hline 4 & FER & $-0.1621^{* * *}$ & 0.0001 & $-0.1919^{* * *}$ & 0.0000 \\
\hline 5 & LBCI & -0.0361 & 0.6310 & 0.0313 & 0.6859 \\
\hline 5 & LCAP & $-0.2029^{* * *}$ & 0.0002 & $-0.1487^{* * *}$ & 0.0071 \\
\hline 5 & LCRI & $0.0899^{*}$ & 0.0831 & $0.0939^{*}$ & 0.0768 \\
\hline 5 & LCI & $-0.0952^{*}$ & 0.0518 & -0.0807 & 0.1035 \\
\hline 5 & LDJSI & $-0.2148^{* * *}$ & 0.0001 & $-0.1899^{* * *}$ & 0.0010 \\
\hline 5 & DY & 0.0527 & 0.3453 & 0.0012 & 0.9829 \\
\hline 5 & LISI & $-0.1874^{* * *}$ & 0.0067 & $-0.1763^{* *}$ & 0.0116 \\
\hline 5 & MCAP & -0.0708 & 0.3090 & -0.0931 & 0.3044 \\
\hline 5 & PER & -0.0583 & 0.2962 & -0.0425 & 0.4435 \\
\hline
\end{tabular}


Next, we implement a robustness check for out-of-sample evaluations. To do so, we use $70 \%$ of data to generate a recursive forecast of the remaining $30 \%$ of the sample. Once again, we compute RTU and OOSR2 to compare the forecasting performance of our proposed macroeconomic predictor-based model with the constant-only model. Results are reported in Table 7. Here, when we increase the estimation window from $50 \%$ to $70 \%$, we find that OOSR 2 provides more favorable results with respect to our proposed macroeconomic predictor-based model visà-vis the constant-only model. For instance, we find that OOSR $2>0$ in 21/30 cases, which implies that 21 macroeconomic-based predictability model outperforms the constant-only model. The exceptions are BY5Y, BY10Y, M1, LCCI, LIP, PP, LCI, DY and MCAP. For these nine variables, the constant-only model outperforms our proposed macroeconomic-based predictor model. These results are quite robust to our in-sample predictability results. Finally, we conclude that LBCI, LCAP, LCRI, LDJSI, LISI, JIBOR1, JIBOR3, JIBOR6, JIBOR12, LM2, and FER significantly predict Indonesia's inflation rate irrespective of in-sample and out-of-sample evaluation, forecasting horizon, and different out-of-sample forecasting periods considered in our study.

Table 7.

Robustness Test for Out-of-Sample Evaluation

This table reports robustness test results for two measures of out-of-sample evaluation, namely the RTU and the OOSR2. For robustness checks, we decrease the out-of-sample period from $50 \%$ to $30 \%$ of the data sample.

\begin{tabular}{lccccccc}
\hline Group & Variables & RTU & OOSR2 & Group & Variables & RTU & OOSR2 \\
\hline 1 & BY1Y & 0.9829 & 0.0102 & 4 & EXPPI & 1.2326 & 0.1929 \\
1 & BY5Y & 1.0018 & -0.0030 & 4 & LIMP & 1.3631 & 0.2097 \\
1 & BY10Y & 1.0116 & -0.0117 & 4 & LIP & 1.0261 & -0.0146 \\
2 & JIBOR1 & 1.2393 & 0.2527 & 4 & LR & 1.3855 & 0.1144 \\
2 & JIBOR3 & 1.1057 & 0.3045 & 4 & PP & 1.1486 & -0.6427 \\
2 & JIBOR6 & 1.1887 & 0.2557 & 4 & FER & 1.0058 & 0.1001 \\
2 & JIBOR12 & 1.0253 & 0.3093 & 5 & LBCI & 1.0088 & 0.0181 \\
3 & LM2 & 0.7591 & 0.4202 & 5 & LCAP & 1.0898 & 0.2837 \\
3 & M1 & 1.0065 & -0.0154 & 5 & LCRI & 1.1205 & 0.2674 \\
4 & LCCI & 1.2208 & -0.3587 & 5 & LCI & 1.0484 & -0.1724 \\
4 & LCIC & 1.0095 & 0.0743 & 5 & LDJSI & 1.0239 & 0.2781 \\
4 & TD3M & 1.0243 & 0.0775 & 5 & DY & 1.0182 & -0.0527 \\
4 & LEXP & 1.2246 & 0.2752 & 5 & LISI & 1.0534 & 0.0704 \\
4 & LER & 1.0536 & 0.2686 & 5 & MCAP & 2.0713 & -19.4317 \\
4 & IMPPI & 1.5455 & 0.0900 & 5 & PER & 0.9988 & 0.0030 \\
\hline
\end{tabular}

\section{CONCLUDING REMARKS}

This paper undertakes an in-sample and out-of-sample predictability analysis of Indonesia's inflation rate using a wide range of macroeconomic predictor variables. More specifically, we use monthly time-series data for 30 macroeconomic variables to examine which variables contain adequate information to statistically significantly predict Indonesia's inflation rate. First, we consider the WN (2012, 2015) in-sample predictability model, which accounts for three salient feature of time-series data (persistency, endogeneity, and heteroskedasticity), which is 
often ignored in the literature. We find evidence that 22 macroeconomic variables statistically significantly predict Indonesia's inflation rate.

Second, we use two measures of out-of-sample evaluation: RTU and OOSR2 statistics. We find less evidence of out-of-sample predictability compared to insample predictability. For 11 macroeconomic variables (LBCI, LCAP, LCRI, LDJSI, LISI, JIBOR1, JIBOR3, JIBOR6, JIBOR12, LM2, and FER), we note evidence of both in-sample and out-of-sample predictability.

Finally, we consider a robustness test for both in-sample and out-of-sample evaluations. Here, we conclude that in-sample evidence of predictability is consistent at three forecasting horizons $h=1, h=3$, and $h=6$. However, the evidence based on out-of-sample evaluation is more favorable to our proposed macroeconomic predictor-based model (vis-à-vis constant-only model) when we increase the estimation window from $50 \%$ to $70 \%$ of the data sample.

\section{REFERENCES}

Barr, D.G., and Campbell, J.Y. (1997). Inflation, Real Interest Rates, and the Bond Market: A Study of U.K. Nominal and Index-Linked Government Bond Prices. Journal of Monetary Economics, 39, 361-383.

Berg, T., and Henzel, S. (2015). Point and density forecasts for the Euro Area using Bayesian VARs. International Journal of Forecasting, 31, 1067-1095.

Caggiano, G., Kapetanios, G., and Labhard, V. (2011). Are More Data Always Better for Factor Analysis? Results for the Euro Area, the Six Largest Euro Area Countries and the UK. Journal of Forecasting, 30, 736-752.

Clark, T., and Ravazzolo, F. (2015). Macroeconomic Forecasting Performance under Alternative Specifications of Time-Varying Volatility. Journal of Applied Econometrics, 30, 551-575.

D'Agostino, A., Gambetti, L., and Giannone, D. (2013). Macroeconomic Forecasting and Structural Change. Journal of Applied Econometrics, 28, 82-101.

Devpura, N., Narayan, P.K., and Sharma, S.S. (2018). Is Stock Return Predictability Time-Varying? Journal of International Financial Markets, Institutions E Money, $52,152-172$.

Duasa, J., Ahmad, N., Ibrahim, M. H., and Zainal, M. (2010). Forecasting Inflation in Malaysia. Journal of Forecasting, 29, 573-594.

Forni, M., Hallin, M., Lippi, M., and Reichlin, L. (2003). Do Financial Variables Help Forecasting Inflation and Real Activity in the Euro Area. Journal of Monetary Economics, 50, 1243-1255.

Giannone, D., Lenza, M., Momferatou, D., and Onorante, L. (2014). Short-Term Inflation Projections: A Bayesian Vector Autoregressive Approach. International Journal of Forecasting, 30, 635-644.

Goodhart, C., and Hofmann, B. (2000). Asset Prices and the Conduct of Monetary Policy, manuscript, London School of Economics.

Groen, J., Kapetanios, G., and Price, S. (2009). Are Al-Time Evaluation of Bank of England Forecasts of Inflation and Growth. International Journal of Forecasting, 25, 74-80. 
Gupta, R., and Kabundi, A. (2011). A Large Factor Model for Forecasting Macroeconomic Variables in South Africa. International Journal of Forecasting, 27, 1076-1088.

Hossain, A. (2005). The Sources and Dynamics of Inflation in Indonesia: An ECM Model Estimation for 1952-2002. Applied Econometrics and International Development, 5-4, 93-116.

Mandalinci, Z. (2017). Forecasting Inflation in Emerging Markets: An Evaluation of Alternative Models. International Journal of Forecasting, 33, 1082-1104.

Öğünç, F., Akdoğan, K., Başer, S., Chadwick, M., Ertuğ, D., and Hülagü, T. (2013). Short-Term Inflation Forecasting Models for Turkey and a Forecast Combination Analysis. Economic Modelling, 33, 312-325.

Phan, D.H.B., Sharma, S.S., and Tran, V.T. (2018). Can Economic Policy Uncertainty Predict Stock Returns? Global Evidence. Journal of International Financial Markets, Institutions and Money, 55, 134-150.

Ramakrishnan, U., and Vamvakidis, A. (2002). Forecasting Inflation in Indonesia. IMF Working paper, No. 02/111.

Salisu, A.A., and Isah, K.O., (2018). Predicting US Inflation: Evidence from a New Approach. Economic Modelling, 71, 134-158.

Sari, N. R., Mahmudy, W. F., and Wibawa, A. P. (2016). Bankpropagation on Neural Network Method for Inflation Rate Forecasting in Indonesia. International Journal of Advances in Soft Computing and its Applications, 8, 70-87.

Sharma, S. S. (2016). Can Consumer Price Index Predict Gold Price Returns? Economic Modelling, 55, 269-278.

Sharma, S.S., Tobing, L., and Azwar, P. (2018). Understanding Indonesia's macroeconomic data: what do we know and what are the implications? Bulletin of Monetary Economics and Banking, 21, 229-264.

Siregar, R., and Rajaguru, G. (2005a). Base Money and Exchange Rate: Sources of Inflation in Indonesia during the Post-1997 Financial Crisis. Journal of Economic Integration, 20, 185-215.

Siregar, R., and Rajaguru, G. (2005b). Sources of Variations Between the Inflation Rates of Korea, Thailand, and Indonesia During the Post 1997 Crisis. Journal of Policy Modeling, 27, 867-884.

Stock, J.H., and Watson, M.W. (2001). Forecasting Output and Inflation: The Role of Asset Prices. Mimeo.

Westerlund, J., and Narayan, P.K. (2012). Does The Choice of Estimator Matter When Forecasting Returns? Journal of Banking and Finance, 36, 2632-2640.

Westerlund, J., and Narayan, P.K. (2015). Testing for Predictability in Conditionally Heteroskedastic Stock Returns. Journal of Financial Econometrics, 13, 342-375.

Wimanda, R. E., Turner., P. M., and Hall, M. J. B. (2011). Expectations and the Inertia of Inflation: The Case of Indonesia. Journal of Policy Modelling, 33, 426438. 
This page is intentionally left blank 